\title{
AVALIAÇÃO DA ESTRUTURA DE GOVERNANÇA NO SISTEMA DE INTEGRAÇÃO DA SUINOCULTURA EMM GOIÁS
}

\author{
Evaluation of the Governance Structure in the Swine Integration System in Goiás
}

\begin{abstract}
RESUMO
Desde a abertura do comércio a partir dos anos 90, a suinocultura brasileira vem ganhando grande relevância na economia nacional. Os estudos que tratam da agricultura contratual se concentram principalmente em grandes contratos orientados para a exportação e que são operados por grandes empresas privadas. Em termos de agricultura contratual, o pequeno produtor ainda é pouco representado na literatura. O objetivo deste estudo é avaliar e analisar a estrutura de governança e os seus mecanismos de coordenação adotados no sistema de integração da suinocultura goiana (Brasil). Para alcançar o objetivo proposto foi utilizado o método de estudo de caso composto por duas granjas de suínos na região de Rio Verde (Goiás). O estudo foi realizado seguindo o pressuposto teórico do alinhamento discriminante da Economia dos Custos de Transação de Oliver Williamson. Os dados de campo indicaram que o mecanismo de coordenação adotado na relação entre produtor e processador se dá por meio de contratos, denominados contratos de integração. O contrato de integração é estruturado com mecanismos garantidores que contribuem para a redução dos custos transacionais e produtivos, ou seja, a agroindústria assegura o suprimento dos suínos, insumos, transporte e assistência técnica e veterinária, e o produtor assegura o fornecimento da produção, atuando assim como um meio de compartilhamento de riscos da atividade produtiva.
\end{abstract}

Francisco Charles Barros Jorge

Universidade Federal de Goiás

fra.charles@hotmail.com

Ricardo Messias Rossi

Universidade Federal de Goiás

rossi.ufg@gmail.com

Cândido Vieira Borges Júnior

Universidade Federal de Goiás

candidoborges@gmail.com

Marco Antonio Conejero

Universidade Federal Fluminense

marco.conejero@gmail.com

Recebido em: 26/05/2020. Aprovado em: 21/04/2021

Avaliado pelo sistema double blind review

Avaliador científico: Eduardo César Silva

DOI: $10.48142 / 2320211655$

\begin{abstract}
Since the opening of trade in the 1990s, Brazilian pig farming has gained great importance in the national economy ever since. The studies dealing with contractual agriculture focus mainly on large export-oriented contracts that are operated by large private companies. In terms of contractual agriculture, the small producer is still underrepresented in the literature. The objective of this study is to evaluate and analyze the governance structure and its coordination mechanisms adopted in the integration system of swine farming in Goiás (Brazil). To achieve the proposed objective, the case study method composed of two pig farms in the region of Rio Verde (Goiás) was elaborated. The study was carried out following the theoretical assumption of Oliver Williamson's discriminating alignment of Transaction Cost Economics. The field data indicated that the coordination mechanism adopted in the relationship between producer and processor occurs through contracts, named integration contracts. The integration contract is structured with guarantee mechanisms that contribute to the reduction of productive costs, that is, the agro-industry ensures the supply of pigs, inputs, transportation and technical and veterinary assistance, and the producer ensures the supply of production, acting as well as a means of sharing risks of the productive activity.
\end{abstract}

Palavras-chave: Pequeno produtor; Economia dos Custos de Transação; Contrato.

Keywords: Small farmer; Transaction Cost Economics; Contract.

Organizações Rurais \& Agroindustriais, Lavras, 23:e1655, 2021 


\section{INTRODUÇÃO}

Os mercados agrícolas em todo mundo estão se reestruturando e passando por grandes mudanças. Por exemplo, o aumento da coordenação e o controle vertical e o uso de contratos de produção e marketing em todas as etapas da cadeia alimentar são cada vez mais estimulados por preocupações com a qualidade e segurança dos alimentos e pela necessidade de garantir ou certificar os atributos de produtos alimentares (Oliveira, Zylbersztajn \& Saes, 2019; Sexton, 2013).

Evidentemente, isso leva os agentes dentro da Cadeia Produtiva a adotarem novas formas de coordenação, incluindo a contratação de pequenos agricultores com transferência de tecnologia interligada, estruturas triangulares com fornecedores de tecnologia ou instituições financeiras ou produção verticalmente integrada (Kuijpers \& Swinnen, 2016).

Como forma de reduzir os possíveis efeitos negativos da cooperação, os agentes integrantes das cadeias produtivas utilizam estruturas de governança e mecanismos de coordenação, contribuindo para o controle e adaptação entre as partes, por exemplo, por meio do uso de arranjos contratuais entre os agentes como redutores de custos de transação (de Almeida, Zylbersztajn \& Klein, 2010; Schepker, Oh, Martynov \& Poppo, 2014).

Com a abertura do comércio a partir dos anos 90, a suinocultura brasileira vem ganhando desde então grande relevância na economia nacional. Em 2018, o país consolidou-se como o quarto maior exportador mundial, com um total de 600 mil toneladas, ficando atrás apenas dos Estados Unidos, União Europeia e Canadá, de acordo com a Associação Brasileira da Indústria Produtora e Exportadora de Carne Suína (ABPA, 2019). Os volumes exportados de carne suína, bovina e de aves aumentaram $16 \%, 15 \%$ e $4 \%$, respectivamente, em 2019. Ao mesmo tempo, os preços (em dólares) das carnes suína, de aves e bovina cresceram $13,6 \%, 5,0 \%$ e 3,7\%, respectivamente (Centro de Estudos Avançados em Economia Aplicada [CEPEA], 2020).

Nessa perspectiva, pode-se citar que o crescimento significativo dos Sistemas Agroindustriais, baseados em contratos com compromissos de garantia no suprimento em quantidade, qualidade e regularidade para o abastecimento da indústria frigorífica e a necessidade cada vez maior de segurança na comercialização para os produtos de origem animal foram determinantes para o avanço de mecanismos de coordenação mais exigentes e eficientes (Sexton, 2013; Sexton \& Xia, 2018).
É neste contexto que este artigo se desenvolve. Trata da eficiência ${ }^{1}$ econômica das estruturas de governança em termos de organização econômica comparativa, seguindo o pressuposto teórico do alinhamento discriminante da Economia dos Custos de Transação de Williamson (1985) no sentido de que a estrutura de governança mais eficiente, como forma de melhor coordenar as relações de troca entre os agentes em uma determinada cadeia, será aquela que promoverá a redução dos custos de transação.

Diversos autores, Alemu, (2017), de Oliveira, Cunha, Caleman \& Maia (2019), Miele e Zylbersztajn (2005), Zhou, Zhou, Qi, Li (2019), fazem uso desses pressupostos, cujo olhar se apresenta de forma que uma coordenação eficaz entre os agentes de uma cadeia produtiva favorece uma vantagem mais eficiente para os sistemas agroindustriais. De maneira semelhante, os estudos existentes que tratam da agricultura contratual se concentram principalmente em grandes contratos orientados para a exportação que são operados por grandes empresas privadas (Meemken \& Bellemare, 2020). O pequeno produtor é dificilmente coberto e, portanto, pouco representado na literatura. Essa é uma lacuna pois esses esquemas podem incluir e afetar mais agricultores do que os grandes esquemas orientados para a exportação.

Em outras palavras este estudo pretende avaliar e analisar a estrutura de governança e os seus mecanismos de coordenação adotados pelo sistema de integração da suinocultura goiana, qual seja, o contrato de integração, e gerar evidências que possibilitem maior entendimento sobre as motivações dos tomadores de decisão em adotar uma ou outra estratégia de governança para reduzir os custos das transações.

Já os objetivos específicos deste estudo são descrever a transação envolvida entre os elos produtor e processador (segundo o modelo teórico da Economia dos Custos de Transação), identificar e caracterizar as estruturas de governança adotadas no Sistema de Integração da suinocultura goiana e efetuar uma correspondência discriminante, para verificar se a estrutura de governança adotada na prática é considerada a mais eficiente, ou seja, se é corroborada pela teoria.

O objeto onde se desenvolve a pesquisa é o Sistema de Integração Suíno do estado de Goiás. A escolha da suinocultura goiana para este estudo se dá pela sua

${ }^{1}$ A eficiência de um Sistema Agroindustrial (SAG) baseia-se em sua capacidade de criar, sustentar e distribuir valor. Para isso, os mecanismos de coordenação são indispensáveis (Caleman, Zylbersztajn, Pereira, \& Oliveira, 2017). 
significância em termos socioeconômicos para o estado de Goiás e, consequentemente, pela importância da necessidade de uma análise e maior aprofundamento das inter-relações contratuais entre os agentes que compõem essa cadeia. Segundo dados fornecidos pela Associação Brasileira dos Criadores de Suínos - ABCS (2019), Goiás é o segundo principal produtor de suínos da região CentroOeste. Sua participação relativa no abate nacional é de $6 \%$, com uma estimativa de 2,5 milhões de cabeças abatidas. Dos abates totais de suínos no Estado, $80 \%$ originam-se nos sistemas integrados, ligados a alguma agroindústria, e o restante é de suinocultores independentes. Dos abates inspecionados, $90 \%$ dos suínos são de produtores integrados. O predomínio desse sistema é reforçado pela presença no Estado dos três maiores conglomerados agroindustriais do país, que sozinhos detêm $90 \%$ dos abates (ABCS, 2019).

Este artigo tem como contribuição auxiliar o pequeno produtor diante do cenário globalizante de alta concentração, especialização e poderio econômico dos grandes processadores, além de fornecer subsídios para a tomada de decisão em torno dos determinantes da estrutura de governança adotada na suinocultura goiana, com o propósito de melhorar integração e coordenação de suas atividades em que propiciem um aumento de eficiência e competitividade.

Este artigo é dividido em cinco seções. $\mathrm{Na}$ próxima seção é apresentada a fundamentação teórica. Na seção três é apresentado o tipo de pesquisa, além da apresentação dos procedimentos adotados para análise do objeto de estudo. A seção quatro é dedicada à apresentação, análise e discussão dos resultados da pesquisa. As considerações finais sobre a pesquisa, os principais resultados obtidos e as possíveis pesquisas futuras sobre a cadeia produtiva suína são expostas na seção cinco.

\section{REFERENCIAL TEÓRICO}

\subsection{Nova Economia Institucional e a Economia dos Custos de Transação}

Para Ronald Coase, no seu clássico artigo "The Nature of Firm" de 1937, os estudos vigentes da época davam pouca importância para organização interna da firma e sua relação com o ambiente (Coase, 1937). Segundo o autor, era necessária uma nova perspectiva teórica, uma vez que o mainstream econômico focava mais na análise da questão "demanda versus produção"2, coordenada pelo sistema de preços, do que com arranjos alternativos de governança e coordenação de produção.

A partir do pioneirismo de Coase, a teoria econômica das organizações evolui e as questões de governança e de mecanismos de coordenação ganham relevância nos estudos acadêmicos, principalmente a partir dos estudos de Direitos de Propriedade, Economia dos Custos de Transação, Visão Baseada em Recursos e Nova Economia Institucional (NEI), destacando-se questões sobre mecanismos de governança baseados na integração vertical, contratos complexos e o papel das instituições (Paulillo \& Neves, 2015; Zylbersztajn, 2017).

Mais precisamente, a NEI estuda as instituições e como elas interagem com as organizações e como essa matriz institucional-organizativa afeta a economia e a sociedade. (North, 1991). Aqui as instituições são entendidas como um conjunto de restrições humanas legadas que se estruturam através das interações políticas e sociais, correspondendo ao sistema de normas hierarquizadas, tanto formais (constituição, leis, regulamentações) quanto informais (normas de conduta, costumes, convenções, tradições, tabus) e sistemas de conformidade que regulam a interação humana na sociedade que estabelecem as bases para a produção, troca e distribuição, também designadas como as regras do jogo ${ }^{3}$ social (Augusto, Souza \& Cario, 2014; North, 1991)

Nesta análise, transações e estruturas de governança são temas centrais, onde as transações, segundo Williamson (1985), correspondem à transferência de bens e serviços através de uma tecnologia interface separável, por exemplo, o contrato de venda da produção de suínos. Já a estrutura de governança, segundo o autor, é definida como um mecanismo controlador estabelecido pelos agentes na forma de coordenação das atividades econômicas com objetivo de garantir ordem para que as transações ocorram como inicialmente planejadas.

A Economia dos Custos de Transação (ECT) considera a transação como unidade de análise, dando a ela um significado operacional, a partir das diferenças das dimensões das transações que as caracterizam. Essas

\footnotetext{
${ }^{2} \mathrm{~A}$ visão ortodoxa dominante na época considerava a firma como uma "black box", ou seja, um local onde as transformações tecnológicas eram mais importantes e maximizadoras de utilidade e lucro e que os aspectos organizacionais, como os relacionamentos entre os fornecedores eram ignorados. (Farina, et al., 1997).

${ }^{3}$ Segundo Williamson (1998), as instituições de interesse principal para NEI são o ambiente institucional, denominado por Douglas North (1991) como regras do jogo - política, judiciário, leis de contrato e propriedade-enquanto as estruturas de governança - mercado, híbridos, firmas e agências - agem como jogadores desse jogo.
} 
dimensões são caracterizadas pelo nível dos ativos específicos envolvidos na relação; pela quantidade da incerteza envolvida no ambiente e pela frequência com que a transação ocorre (Williamson, 1998).

\subsection{Transações e suas Dimensões}

Para a ECT, as transações são organizadas em estruturas de governança que variam dentro de um continuиm, isto é, entre estrutura de mercado e hierarquia, e a escolha de determinada estrutura de governança dependerá das características da transação, ou seja, especificidade do ativo, incerteza e frequência. $\mathrm{O}$ foco aqui então é procurar a minimização dos custos envolvidos nas transações através de mecanismos de governança eficientes para apoiar transações econômicas (He, Lin \& Wei, 2016; Williamson, 1991).

No estudo das dimensões das transações, a frequência relaciona-se com a regularidade com que ocorre determinada transação, podendo ser classificada em recorrente ou ocasional. Já a incerteza está relacionada diretamente com assimetria informacional e em quão custosa é a identificação de informações por parte dos envolvidos em uma determinada transação, abrindo possibilidade de comportamento oportunista. Em relação aos ativos específicos, Williamson (1985) define quanto ao nível de dependência de um ativo está em relação à possibilidade de utilização alternativa do mesmo, sem, contudo, ocorrer perda de valor econômico desse ativo (Martins, Trienekens, \& Omta, 2017; Verbeke \& Kano, 2013; Williamson, 1998).

A especificidade dos ativos nas transações é o atributo mais crítico na formação das estruturas de governança, pois é por meio dela que se gera a dependência bilateral. Em outras palavras, os níveis de grau de especificidade de ativos são responsáveis pelas diferenças encontradas nos custos de transação, isto é, quanto mais específicos os ativos forem, maior será o custo de transação, porque mais salvaguardas devem ser introduzidas no conteúdo e no processo de contratação para proteger o proprietário do ativo específico contra perdas econômicas agindo, assim, como um mecanismo de proteção para transações comerciais (Higashi, Fagundes, Caleman, Sauer \& Saes, 2017; Lui, Wong \& Liu, 2009; Poppo \& Zenger, 2002; Verbeke \& Kano, 2013; Williamson, 1991; 2008).

\subsection{ECT e os Pressupostos Comportamentais}

A ECT assume a natureza humana como ela é realmente, caracterizada pela racionalidade limitada e por oportunismo. Por racionalidade limitada entende-se as competências cognitivas para assimilação das informações do ambiente e por oportunismo a propensão pela busca de interesse próprio com malícia do ser humano (Williamson, 1985).

Uma das consequências da racionalidade limitada é a sua impossibilidade de processar todas as informações necessárias à elaboração de contratos completos, abrindo margem para o aparecimento de distúrbios ex-ante que surgem em função dessa incompletude contratual, tais como, lacunas, erros ou omissões contratuais não previstas no contrato original, originando negociações ou adaptações contratuais ex-post (Azevedo, 2000; Breitenbach \& Souza, 2015a; Higashi et al., 2017; Silva \& Brito, 2013; Williamson, 1998; 2007).

Para Williamson (1985), oportunismo entende-se como uma ação de indivíduos, de forma maliciosa, egoísta e aética, na busca do seu auto interesse, ou seja, uma busca de maior benefício próprio por uma das partes numa transação (Azevedo, 2000; Zylbersztajn, 1995).

\subsection{Estruturas de Governança}

A estrutura de governança é definida como um mecanismo controlador estabelecido pelos agentes na forma de coordenação das atividades econômicas com objetivo de garantir ordem para que as transações ocorram como inicialmente planejadas (Williamson, 1985).

Seguindo a mesma linha de raciocínio de Williamson (1985), Zylbersztajn (1995) destaca que as estruturas de governança são o resultado otimizado pela busca de eficiência a partir do alinhamento dos atributos das transações com o ambiente institucional. Em outras palavras, a escolha da governança é a otimização em relação aos custos de transação (Dagdeviren \& Robertson, 2016).

Em termos gerais, a estrutura de governança parte dos atributos das transações (especificidade dos ativos, incerteza e frequência), juntamente com os pressupostos comportamentais da NEI (racionalidade limitada e oportunismo), e dentro desse arcabouço institucional decide qual é a melhor estrutura que se adequa para a organização gerenciar suas transações (Soares \& Saes, 2015).

Williamson $(1985 ; 1991)$ destaca que as formas organizacionais (estruturas de governanças) podem ser coordenadas da seguinte maneira: a) estrutura de mercado; b) estrutura hierárquica (firma, integração vertical); c) estrutura híbrida. Estas estruturas são descritas a seguir. 
Estrutura de governança via mercado é caracterizada pelas regras estabelecidas no mecanismo de preços, ou seja, as negociações são estabelecidas em negociações pontuais, mais simples, sem excedentes em relação ao direito contratual que não seja obrigação de entregar o bem ou serviço contratado, baixo risco de oportunismo. Sem relação de dependência entre os compradores e vendedores, com baixo grau de especificidade de ativos e baixa incerteza das transações (Breitenbach \& Souza, 2015b).

A estrutura hierárquica ou integração vertical é caracterizada pelo aumento das especificidades dos ativos ocasionando maiores riscos de oportunismos nas trocas comerciais, exigindo daí maior capacidade de adaptação. Busca-se por meio de salvaguardas contratuais a internalização das operações, assumindo total controle dos fatores e graduação de autoridade (Williamson, 1991).

A estrutura de governança híbrida ${ }^{4}$ refere-se a organizações na faixa intermediária entre as que não recorrem nem ao sistema de preços diretamente e nem a estrutura hierárquica (Ménard, 2004; Williamson, 1991). São exemplos: alianças, acordos de licença, franquias, joint-ventures.

\subsection{Hipótese do Alinhamento Discriminante de Williamson}

A lógica predominante na hipótese do alinhamento discriminante é que “(...) as transações, que diferem em seus atributos, alinham-se com as Estruturas de Governança, que diferem em seus custos e competências; de forma discriminatória, principalmente reduzindo os custos de transação" (Williamson, 1985, p. 138, tradução nossa).

A presença de atributos organizacionais diferentes demandaria estruturas de governança que se diferenciariam em termos de custos e capacidade adaptativas. A eficiência organizacional seria uma correspondência entre estruturas de governança com atributos da transação. Com isso, dentro do contexto da complexidade do ambiente institucional, a empresa alinha sua estrutura de governança para conduzir suas transações a partir das dimensões das transações (frequência, incerteza e especificidade dos ativos) em conjunto com

${ }^{4}$ Essa estrutura híbrida se desenvolve porque os mercados não são capazes de gerir adequadamente os recursos e as capacidades importantes para o negócio. Assim, o compartilhamento de alguns recursos e a coordenação de algumas decisões são os motivadores por trás da formação da estrutura híbrida (Ménard, 2018). os pressupostos comportamentais (racionalidade limitada e oportunismo) (Ambrozini \& Martinelli, 2017; Soares \& Saes, 2015).

\section{METODOLOGIA}

Utilizou-se de uma abordagem qualitativa, na qual apresenta-se com uma forma mais engajada para o estudo da realidade (Denzin \& Lincoln, 2006, p. 17). Quanto aos objetivos, a metodologia utilizada teve caráter exploratório e descritivo, uma vez que mescla a descrição da estrutura de governança no Sistema de Integração Suíno Goiano e a verificação das características da transação realizada. Para um melhor entendimento do objeto desta pesquisa, apresenta-se um modelo simplificado (Figura 1), apresentado por Zylbersztajn (2000), de um sistema agroindustrial e suas transações típicas.

Assim, o foco desta pesquisa foi descrever a transação T2, aqui definida como o resultado da produção de suínos no modelo de integração, seguindo os pressupostos teóricos nos termos de Williamson (1991). Após a descrição das dimensões da transação, buscou-se analisar as estruturas de governança usadas para controlar a Transação T2 e, por fim, aplicar a hipótese do alinhamento discriminante de Williamson.

Para alcançar os objetivos inicialmente propostos foi utilizado o método de estudo de caso, que pode ser utilizado em diversos objetivos, como, por exemplo, prover uma descrição de algum fenômeno, gerar ou testar uma teoria, além de ser o método mais adequado para o estudo aprofundado de um fenômeno em seu contexto da vida real (Eisenhardt, 1989).

A presente pesquisa se apresenta de corte transversal, uma vez que esse tipo de corte considera o momento no qual a coleta de dados é realizada. A pesquisa utilizou-se tanto de dados primários (entrevistas) quanto de dados secundários (documentos). $\mathrm{O}$ estudo de caso foi realizado em granjas de suínos no estado de Goiás, na região de Rio Verde (GO). Foram analisadas duas granjas de suínos. Os critérios para a seleção dos entrevistados foram:

- produtores que comercializam formalmente no Sistema de Integração Suíno Goiano;

- produtores que mantêm relações comerciais (acordos e contratos).

A partir da realização das quatro entrevistas semiestruturadas, ocorreu a transcrição dos dados coletados, conforme proposto por Bardin (2004). Nesta 
Ambiente Organizacional: Associações, Informação, Pesquisa, Finanças, Cooperativas, Firmas

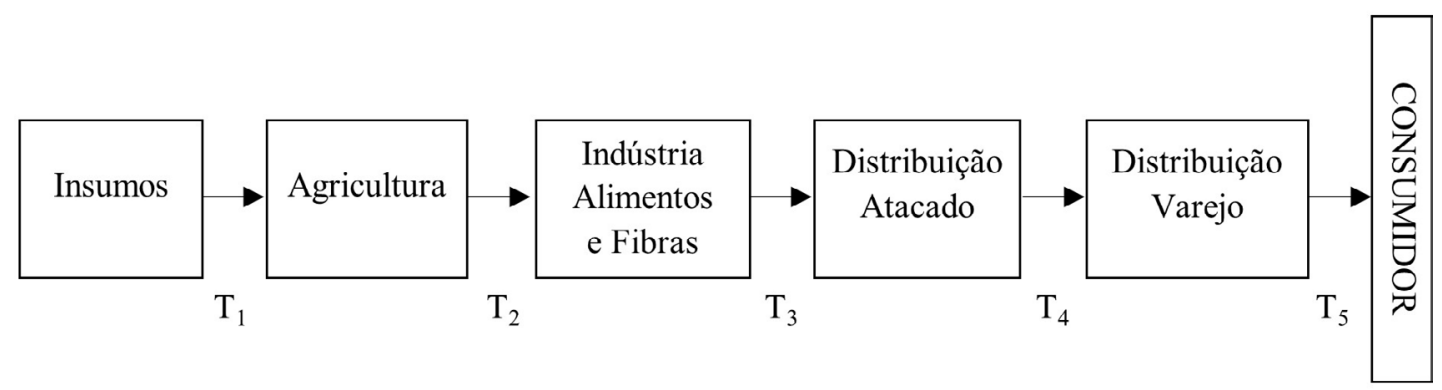

Ambiente Institucional: Cultura, Tradições, Educação, Costumes

FIGURA 1 - Modelo Simplificado de um sistema agroindustrial

Fonte: Zylbersztajn (2000, p.14)

QUADRO 1 - Caracterização das entrevistas.

\begin{tabular}{|c|c|c|c|}
\hline Entrevistado & Cargo/ocupação & Data da entrevista & Duração \\
\hline Produtor 1 & Proprietário - Empresário Rural (Granja n ${ }^{\text {1) }}$ & $01 / 03 / 2020$ & 62 minutos \\
\hline Produtor 2 & Proprietário - Empresário Rural (Granja n ${ }^{\circ}$ 2) & $08 / 03 / 2020$ & 49 minutos \\
\hline Especialista 1* & $\begin{array}{c}\text { Diretor da AGIGO (Associação dos Granjeiros } \\
\text { Integrados do Estado de Goiás) }\end{array}$ & $02 / 03 / 2020$ & 53 minutos \\
\hline Especialista 2** & Gerente de Produção da Granja n ${ }^{\circ} 2$ & $08 / 03 / 2020$ & 41 minutos \\
\hline
\end{tabular}

*Executivo de uma importante associação setorial da suinocultura

**Gestor (funcionário da Granja $\mathrm{n}^{\circ} 2$ ) com vasta experiência na suinocultura

Fonte: Elaborado pelos autores

pesquisa, as categorias de análise foram definidas a priori, tendo como base a fundamentação teórica realizada, sendo essas: (a) ambiente institucional; (b) transação; (c) incerteza; (d) frequência; (e) especificidade de ativos; (f) estruturas de governança. Convém destacar que a transação, que foi objeto de identificação, análise e interpretação, é a que envolve diretamente o elo produtor e processador, não sendo objeto de análise as transações que envolvem outros elos do sistema agroindustrial. O Quadro 1 mostra as características das entrevistas.

Para fins de alcançar os objetivos propostos, foi utilizada a metodologia de Análise Estrutural Discreta Comparativa de Zylbersztajn (1995). Segundo o autor, esta metodologia permite que formas alternativas de organização (mercado versus hierarquia) sejam comparadas, mais precisamente, "busca relacionar os atributos das transações com as formas de organização mais eficientes em termos de economia de custos de transação e produção" (ZYLBERSZTAJN, 1995, p. 69).

\section{RESULTADOS E DISCUSSÃO}

Esta seção tem como objetivo descrever e analisar os atributos da transação presente na relação do produtor com Agroindústria no Sistema de Integração ${ }^{5}$ Suíno Goiano por meio do contrato de integração estabelecido entre as partes. De início, o modelo organizacional estudado na pesquisa é o do Modelo de Integração. Neste tipo de modelo, a agroindústria é responsável pelo fornecimento de insumos, assistência técnica e veterinária, ração e medicamentos, ou seja, dá todas as condições para a produção. Já para o produtor integrado, ele é responsável pelo manejo da produção, fornecendo a estrutura, terreno, galpões, mão de obra, energia elétrica e água (Miele \& Waquil, 2007).

${ }^{5} \mathrm{~A}$ integração da produção por meio de contratos ou programas de fomento é a forma mais difundida de coordenação da transação entre suinocultores e agroindústria de abate e processamento nos principais países produtores de carne suína, inclusive no Brasil, e sua participação e importância vêm crescendo nas duas últimas décadas (Miele \& Waquil, 2007). 


\subsection{Pressupostos Comportamentais}

A abordagem da NEI para a ECT é baseada em dois pressupostos comportamentais, um envolvendo as competências cognitivas para assimilação das informações (racionalidade limitada) e o outro é a propensão pela busca de interesse próprio com malícia (oportunismo) (Williamson, 1991). Neste sentido, a pesquisa de campo buscou entender como os pressupostos comportamentais, racionalidade limitada e oportunismo, se apresentam nas relações entre os agentes da cadeia, mais precisamente no elo produtor, e como esses pressupostos influenciam a transação.

Quanto à racionalidade limitada, a pesquisa identificou que os produtores se mantêm minimante informados dentro do seu ambiente de negócio, via associação de produtores. Por exemplo, os produtores se queixam de falta de informações sobre preço de mercado pelo lado da agroindústria. Essa observação é relatada nas falas dos produtores: "nós nunca vamos lá negociar um produto sozinhos... nós temos uma representação, que é a associação" (Produtor 1). Já o Produtor 2 observa que "a associação faz um meio termo, um intercâmbio, entre o produtor e empresa e, vamos dizer assim, a associação nossa defende os nossos interesses, tá!" (produtor se referindo à negociação de preço de mercado).

Já em relação ao oportunismo, a pesquisa identificou alguns comportamentos oportunistas, por exemplo, variações de qualidade, composição de preço mercado, custo de insumos. A ação oportunista ex ante (na forma de seleção adversa, pré-contratual) sobre a composição de preço de mercado foi relatado pelo Produtor 1: "Ela montou um esquema para você ter uma ideia, ela começou o cálculo 10 anos pra trás para fazer agora... se nós aceitasse (sic) daqui a 10 anos nós ia tá (sic) tudo obsoleto... e nós não ia (sic) ter renda."

Destaca-se que a dependência econômica presente na relação do produtor com a agroindústria abre a possibilidade de ação oportunista para a Agroindústria. Por exemplo, são fontes de comportamento oportunista situações como o pagamento do financiamento feito para atender a demanda da agroindústria ou a possibilidade de rompimento contratual, a qualquer momento, sem justa causa, com isso os produtores acabam aceitando adaptações ex-post por causa dessa dependência presente na relação.

\subsection{Dimensões da Transação}

\subsubsection{Especificidade dos Ativos}

Para esta pesquisa buscou-se compreender como a especificidade do ativo afeta as transações entre os produtores e a agroindústria. Para tanto, foram analisados os aspectos inerentes da produção de suínos nas granjas. Williamson $(1985,1991)$ afirma que a especificidade dos ativos nas transações é o atributo mais crítico na formação das estruturas de governança, para o autor, a especificidade do ativo pode ser avaliada pelos seis métodos seguintes: local, físico, humano, dedicado, temporal e marca ${ }^{6}$, que foram analisados e discutidos nesta seção do estudo.

Especificidade de local (geográfica) refere-se àqueles ativos em que apresentam a localização como atributo característico. Por exemplo, quanto menor for a distância entre o produtor e o processador envolvidos na transação, maior será a especificidade de local do ativo. No ambiente de pesquisa foi verificado que a distância média das duas granjas pesquisadas até o processador é de 25 quilômetros $(\mathrm{km})$, a granja $\mathrm{n}^{\circ} 1$ com uma distância de $28 \mathrm{~km}$ e a granja $\mathrm{n}^{\circ} 2$ com uma distância de $22 \mathrm{~km}$. Convém destacar que parte dessa distância é percorrida em estradas de chão, de terra batida, o que ocasiona custos de logística, por exemplo, elevação do consumo de combustível, manutenção e tempo de percurso.

Em considerações gerais a localização foi um fator reiterado pelos produtores como determinante para a escolha da agroindústria. Uma vez que a coleta dos suínos nas granjas produtoras é realizada pela agroindústria, os custos logísticos, de controle ou de monitoramento são reduzidos. No entanto, a possibilidade de uso alternativo de escoamento da produção de suínos, por exemplo, através do mercado independente (mercado spot) sugere que a especificidade locacional do SAG Suíno Goiano não seja classificada como alta, e sim média.

Especificidade Física refere-se aos ativos destinados a um determinado fim. No caso da relação entre produtor de suínos e agroindústria, as características propriamente ditas da produção indicam um grau médio de especificidade de ativos físicos, uma vez que a produção de suínos é especialmente moldada para uma destinação específica. Tal fato pode ser observado na fala do seguinte entrevistado: "bem dizendo, é um elefante branco, se não criar porco ali dentro... só se criar jacaré, rã (risos)" (Especialista 2).

Ressalta-se que as especificidades dos ativos físicos das duas granjas são praticamente idênticas, são compostas por dois galpões destinados à gestação, uma composteira, lagoas de dejetos, uma barreira sanitária e o cinturão verde. No entanto, a pesquisa constatou que os ativos físicos destinados na produção de suínos também podem

${ }^{6}$ Neste estudo não foi considerado a especificidade de marca por considerar o suíno como uma commodity. 
ser utilizados para produção de frangos, possibilitando um uso alternativo para determinado fim, caracterizando a especificidade física como média.

Especificidade de capital humano refere-se aqueles ativos relacionados ao conhecimento especializado para desempenhar uma determinada atividade, por exemplo, habilidades técnicas, conhecimentos específicos. $\mathrm{Na}$ pesquisa, foi questionado aos produtores participantes há quanto tempo se dedicam a atividade agrícola. Constatouse que os produtores apresentam uma alta especificidade de capital humano, ambos trabalham na produção de suínos por mais de 15 anos, possuindo um alto nível de conhecimento técnico, conforme ficou constatado nos relatos a seguir: "Eu trabalho desde... 1979, 1980; lá no Sul, meus pais eram, meus irmãos são, eu sou" (Produtor 1); "Desde 2003" (Produtor 2).

Especificidade de Ativos Dedicados refere-se aqueles ativos especiais utilizados para uma transação específica. $\mathrm{Na}$ pesquisa foram observados os ativos dedicados que são próprios para a realização da atividade produção de suínos, por exemplo, os equipamentos e as instalações das granjas. Segundo os produtores pesquisados, os ativos físicos e os dedicados são considerados os maiores investimentos para atender a produção. Como já exposto na especificidade dos ativos físicos, aqui, o nível de especificidade dos ativos dedicados é moderado, uma vez que tais ativos também podem ser utilizados para fins diversos do que propriamente para a produção de suínos, por exemplo, a produção de frangos.

Especificidade Temporal refere-se aqueles ativos relacionados com o tempo em que ocorre a transação. $\mathrm{Na}$ produção agropecuária, são aqueles ativos que devido à alta perecibilidade dos produtos se não transacionarem no tempo certo podem comprometer o processo produtivo, aumentando os custos de transação. Essa preocupação pode ser percebida na fala do Produtor 1: "se dar um problema sanitário aqui na minha granja de suínos e morrer animais demais e não chegar ao padrão ela (a agroindústria) vai pagar abaixo do padrão, o mínimo necessário que seria para minha subsistência. [...] é assim que funciona".

Segundo dados da pesquisa, os contratos estabelecidos entre os produtores e agroindústria apresentam especificações referentes aos prazos e volumes a serem atendidos pelos produtores. No entanto, devido a maturação de todo o processo de produção, indo da engorda até o abate, esse processo é demasiadamente longo, diferentemente de produtos mais perecíveis. Neste caso, a pesquisa constatou que especificidade temporal é moderada.

\subsubsection{Frequência}

A frequência relaciona-se com a regularidade da transação, ou seja, é o número de vezes que dois agentes realizam transação, que pode ocorrer uma única vez ou de maneira recorrente (Williamson, 1985). Nesta pesquisa, a frequência foi definida como recorrente com base nos critérios definidos nos contratos de integração entre os produtores e a agroindústria, principalmente, por envolver animais, tanto de reprodução quanto para o abate, insumos, rações e medicamentos, além de assistência técnica e estrutura logística, conforme relatado na entrevista do Produtor 1: "o que a gente vai entregar para agroindústria é o que a agroindústria vai exigir (referindo ao contrato). Se ela exigir um animal de cem quilos, a gente vai entregar de cem quilos."

\subsubsection{Incerteza}

Segundo dados da pesquisa, os principais fatores de incertezas encontradeos na relação entre produtor e agroindústria foram os seguintes: mudança dos padrões exigidos pela agroindústria para entrega; alterações sobre o nível de qualidade exigido; o próprio processo de produção; as condições de mercado que requerem uma nova estratégia de produção; uma mudança institucional, como alteração de norma sanitária ou ambiental.

De fato, a pesquisa identificou que o ambiente de incerteza na relação entre o produtor e a agroindústria não pode ser desprezado, uma vez que é fator para aumento dos custos de transação. No entanto, a incerteza identificada para o produtor está mais relacionada aos aspectos de produção, por exemplo, quanto fornecimento do combinado nos moldes do contrato. O sistema de integração ajuda a minimizar as incertezas de mercado, conforme ilustrado na seguinte fala: "o produtor que entra no sistema de integração tem uma redução do risco relativo ao mercado e as oscilações de preços de insumos (Especialista 1).

Conforme dados da pesquisa, o Quadro 2 mostra um resumo indicando a relação do grau de especificidade de ativos, o grau de frequência e o grau de incerteza das transações em termos teóricos de Williamson (1985, 1996) com base em critérios encontrados nas entrevistas realizadas com os produtores integrados.

\subsection{Estruturas de Governança}

Segundo dados da pesquisa, o contrato assim estabelecido entre os dois elos traz como vantagem mecanismos garantidores de exigências de garantia 
de fornecimento em tempo e volume pelo lado do processador. Por outro lado, a garantia de remuneração, a partir de uma base de preço já acordado e a garantia de recebimento pela produção do lote de suínos, atuando, portanto, com proposito de manter as relações autônomas a fim de reduzir o oportunismo, mas com a presença de uma dependência bilateral, isto é, de salvaguardas.

De acordo com os pontos destacados nas entrevistas, as principais medidas tomadas para tentar reduzir o nível de oportunismo na transação pelo lado do produtor são:

- inclusão de cláusulas contratuais que explicam como as divergências em torno da transação podem ser resolvidas;

- formatação de contratos de longo prazo com objetivo de recuperar os investimentos específicos de ativos;
- criação de laços de confiança, construção de relacionamentos entre os agentes pelos contratos de longo prazo.

Percebe-se que a relação dos agentes da cadeia está baseada em três pilares: (a) incentivos, através da presença de cláusulas de remuneração, de bônus por meta; (b) poder de autoridade, baseado, principalmente, por meio de um poder econômico pelo lado do processador, por exemplo, quando o Produtor 2 diz: "os animais não são meus, são da empresa, e eu recebo por cabeça, recebo por resultado, e então eu tenho que fazer o suíno ganhar mais peso com o menor consumo e ter melhor resultado... nós seguimos rigorosamente o que eles determinam a ser (sic) feito"; (c) por último, certo nível de adaptabilidade contratual, baseado nos relacionamentos de longo prazo e de confiança existente entre os dois elos.

QUADRO 2 - Atributos da transação encontrados no estudo de caso

\begin{tabular}{|c|c|c|c|}
\hline \multirow{2}{*}{ Atributos da transação } & \multicolumn{3}{|c|}{ Grau definido de acordo com a pesquisa } \\
\hline & Baixo & Médio & Alto \\
\hline $\begin{array}{l}\text { Especificidade de local } \\
\quad \text { (geográfica): }\end{array}$ & & $\begin{array}{l}\text { Embora a localização da produção seja considerada } \\
\text { estratégica para o produtor, permitindo redução de } \\
\text { custos logísticos, a possibilidade de uso alternativo } \\
\text { de escoamento da produção de suínos, por exemplo, } \\
\text { por meio do mercado independente ou o surgimento } \\
\text { de outra agroindústria na região sugere que a } \\
\text { especificidade locacional seja classificada como média. }\end{array}$ & \\
\hline Especificidade Física & & $\begin{array}{c}\text { As características da produção exigem uma } \\
\text { dependência de ativos físicos como terrenos e } \\
\text { estruturas. No entanto, essas características encontradas } \\
\text { não as impossibilitam de uso alternativo como, por } \\
\text { exemplo, na produção de frangos. }\end{array}$ & \\
\hline $\begin{array}{l}\text { Especificidade de capital } \\
\text { humano }\end{array}$ & & & $\begin{array}{l}\text { Produtores com alto nível } \\
\text { de conhecimento técnico. }\end{array}$ \\
\hline $\begin{array}{l}\text { Especificidade de Ativos } \\
\text { Dedicados }\end{array}$ & & $\begin{array}{l}\text { A estrutura exigida para produção de suínos a } \\
\text { possibilita o uso alternativo de produção. }\end{array}$ & \\
\hline Especificidade Temporal & & $\begin{array}{l}\text { Por apresentar perecibilidade média, característica da } \\
\text { produção de suínos. }\end{array}$ & \\
\hline Frequência & & $\begin{array}{l}\text { Evidencia-se uma recorrência média nas transações em } \\
\text { virtude da longa cadeia de maturação do rebanho suíno } \\
\text { e das condições propostas no contrato de integração. }\end{array}$ & \\
\hline Incerteza & & $\begin{array}{l}\text { A incerteza identificada para o produtor está mais } \\
\text { relacionada aos aspectos de produção, por exemplo, } \\
\text { quanto fornecimento do combinado nos moldes do } \\
\text { contrato. Como os contratos são estabelecidos de longo } \\
\text { prazo acaba minimizando os efeitos da incerteza nas } \\
\text { transações. }\end{array}$ & \\
\hline
\end{tabular}

Fonte: Adaptado de Williamson $(1985,1996)$ com os dados encontrados na pesquisa 
Essa assimetria de poder, representada basicamente pelo poder econômico do agente processador, faz do produtor o elo mais fraco da relação. O medo de perder a parceria, o contrato, faz com que o produtor se sujeite a determinadas condições evitando assim algum tipo de sanção, como destacado pelo Especialista 2, "a empresa exigiu que todas as granjas tinham que ter hidrômetro, foi instalado hidrômetro. Como a gente diz, a gente faz porque é a empresa, até porque se não fizer vem aquela represália e aquela conversa toda". Esse relato vai de encontro com Ménard (2004), quando afirma que as assimetrias potenciais no poder de barganha podem resultar, principalmente se o arranjo for organizado em torno de um líder, uma ameaça à continuidade da relação. Portanto, a sujeição pelo produtor dessas atitudes oportunistas, como ficou evidenciado pelas entrevistas, faz com o que o produtor acabe concordando com esse tipo de comportamento, evitando uma perda maior, como o término do contrato de parceria.

O Contrato de Integração, apesar desse grau de adaptabilidade, não é indefinidamente elástico, com bem diz Williamson (1991) se referindo aos contratos neoclássicos. Segundo relatos dos entrevistados, quando acontece algum tipo de perturbação durante o contrato, que pode provocar alguma tensão entre os agentes, a associação dos produtores entra como papel de árbitro, mas quando ela não consegue o realinhamento do relacionamento, tentando apaziguar as tensões, arbitragem dá lugar ao litígio.

\subsection{Hipótese do Alinhamento Discriminante}

Nas seções anteriores foram definidas a unidade de análise e seus principais atributos referentes à transação pesquisada. A partir dessa abordagem, ela nos permite, pela aplicação do teste de hipótese de alinhamento discriminante de Williamson, definir se a estrutura de governança mais eficiente no contexto da transação pesquisada está alinhada com os atributos da transação.

A transação T2 em questão é suportada por investimentos em ativos específicos de média intensidade, como ficou evidenciado na pesquisa. Em relação à frequência que envolve a transação, destaca-se que ela é recorrente, de acordo com os dados da pesquisa. Com base nesses condicionantes, a Figura 2 demonstra, em função do nível de especificidade do ativo com os custos de transação, qual a melhor estrutura de governança para governar a transação T2.

Considerando o momento A, como anterior à formalização do contrato de integração entre o produtor e processador, ou seja, transações realizadas via mercado, percebe-se um nível mais baixo de especificidade de ativos, isto é, $\mathrm{K}_{1}$ menor do que $\mathrm{K}_{2}$. Nesta situação, a estrutura de mercado é a mais eficiente. O baixo nível de especificidade não exige maiores níveis de salvaguardas contratuais, devido ao risco de oportunismo baixo.

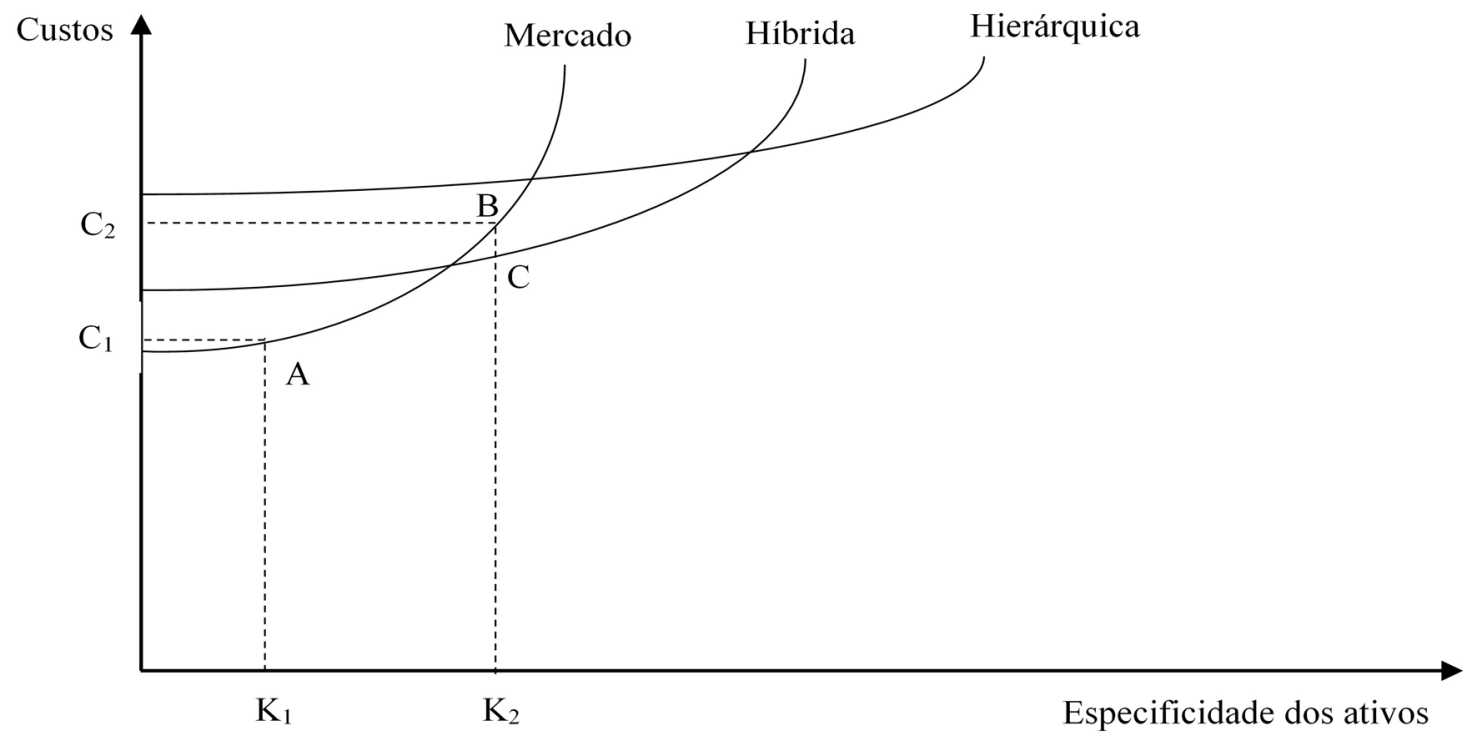

FIGURA 2 - Indução das formas de governança a partir da análise dos custos de transação e especificidade dos ativos Fonte: Adaptado de Zylbersztajn (1995)

Organizações Rurais \& Agroindustriais, Lavras, 23:e1655, 2021 
Já considerando o momento $\mathrm{B}$, como posterior à formalização do contrato de integração entre o produtor e processador, percebe-se um aumento no nível de especificidade de ativos, como mostrado na pesquisa, isto é, $\mathrm{K}_{2}$ maior do que $\mathrm{K}_{1}$, nesta situação existe um aumento da dependência bilateral, o que ocasiona cada vez mais riscos para a contratação, resultando da inclusão controles burocráticos para as salvaguardas contratuais, e isso ficou evidente nos relatos dos entrevistados.

Em contrapartida, o aumento da dependência bilateral tem como consequência um maior nível de controle resultando daí mecanismos de coordenação mais eficientes do que a estrutura de mercado pode oferecer, por exemplo, através da inclusão de cláusulas de monitoramento dos ativos envolvidos no processo produtivo. Portanto, temos um custo de transação maior $\left(\mathrm{C}_{2}\right.$ maior do que $\left.\mathrm{C}_{1}\right)$.

Por fim, considerando o momento $\mathrm{C}$, como alternativa entre estrutura de mercado e estrutura hierárquica, percebe-se que, mantendo o mesmo nível de especificidade de ativos, a estrutura híbrida apresenta um custo de transação maior do que a estrutura de mercado, principalmente por causa das cláusulas de controles de produção exigidos no contrato de integração dos altos níveis de especificidade dos ativos, mas inferior a estrutura hierárquica.

\section{CONCLUSÕES}

Os dados de campo indicaram que o mecanismo de coordenação adotado na relação entre produtor e processador se dá por meio de contratos, denominados contratos de integração. O contrato de integração é estruturado com mecanismos garantidores que contribuem para a redução dos custos produtivos, ou seja, a agroindústria assegura o suprimento dos suínos, insumos, transporte e assistência técnica e veterinária, e o produtor assegura o fornecimento da produção, atuando assim como um meio de compartilhamento de riscos da atividade produtiva.

Não se trata apenas de mais um contrato de compra e venda, é mais do que isso, o contrato de integração é baseado em relacionamentos de longo prazo, o que possibilita a redução dos custos de transação. Pode-se dizer que o contrato serve como facilitador das condições impostas pelo processo de troca de direitos de propriedade, uma proteção para os agentes transacionarem e um instrumento útil na solução de conflitos.
Pela sua análise, percebeu-se que os atributos transacionais presentes, especificidade de ativos, frequência e incerteza foram incorporados ao contrato e por consequência contribuíram para a redução dos custos de transações, o que confirma, no final da pesquisa, a hipótese central da Economia dos Custos de Transação.

De fato, demonstrou-se que o contrato de integração tem as características de média especificidade de ativos, frequência recorrente e incerteza moderada. É de se notar, por exemplo, que o nível alto da especificidade de ativos envolvidos é decorrente do modo de produção exigido para atender tal fim estabelecido no contrato de integração. Já para os atributos incerteza e frequência também foram valorizados durante a realização da pesquisa. A incerteza proveniente do ambiente é a mais presente, decorrente principalmente das oscilações de mercado, questões sanitárias e produtivas. Já para frequência, o estudo a caracterizou como do tipo recorrente, também característica do modo de produção exigido para atender as exigências do contrato de integração.

Os resultados da pesquisa corroboram com a tese da governança híbrida de Williamson nos seguintes pontos:

- diferentemente do que os contratos clássicos preconizam, que a identidade das partes é irrelevante, na governança híbrida a identidade das partes é relevante principalmente pela característica da relação de longo prazo do contrato de integração;

- na governança híbrida encontra-se certo nível de autonomia dos agentes, ao mesmo tempo em que busca garantir incentivos para estes nas transações, por exemplo, pelos investimentos realizados para atividade produzida e que precisam ser depreciados.

- na governança híbrida há um incentivo para arbitragem em desfavor do litígio, diferente do que ocorre na governança de mercado em que a solução de conflitos se dá por meio de contratos formais padronizados devidos ao baixo nível de ativos específicos e com frequência ocasional ou recorrente.

Em relação à estrutura de governança, o estudo identificou que a forma encontrada foi a híbrida, representada pelo contrato de integração, o que vai de encontro com o entendimento de Ménard (2004) a respeito das estruturas híbridas. Segundo o autor, essas estruturas se desenvolvem quando os investimentos específicos são compartilhados entre as partes sem perder autonomia nas decisões e quando as incertezas são tão elevadas que acabam por gerar diversos problemas de coordenação nas transações. 
Como discutido, o contrato de integração é um contrato neoclássico, segundo os pressupostos teóricos de Williamson, apresentando características de um relacionamento de longo prazo, com o objetivo de desenvolver uma relação contínua por causa da dependência bilateral, e de mecanismos de adaptação, decorrentes dos distúrbios que possam ocorrer durante esse relacionamento, por isso a ação da arbitragem como meio para solucionar esses conflitos.

O princípio da reciprocidade e da confiança, que favorecem os processos de adaptação dentro dessa estrutura, ficam prejudicados diante do poder econômico ou financeiro do agente processador, isso pode decorrer, dentre outros fatores, das poucas alternativas economicamente viáveis para os produtores, como cláusulas remuneratórias mais prejudiciais, que por não terem outra opção acabam aceitando.

Em relação às limitações da pesquisa, cabe destacar a limitação do ponto de vista da falta de informações provenientes do elo da agroindústria. Em relação às contribuições teóricas, esta pesquisa complementa estudos anteriores de estruturas de governança em Sistemas Agroindustriais, mas avançando sobre o tema da Suinocultura no estado de Goiás, em virtude dos poucos trabalhos em torno deste contexto específico. Além de tratar a estrutura de governança no âmbito de decisão estratégico pelas partes envolvidas e como isso afeta a relação com a agroindústria. Argumenta-se também o papel da assimetria de poder na relação dentro do SAG Suíno, o que acaba moldando as relações entre o produtor - processador em função do que tem maior poder. Esse desequilíbrio afeta a eficiência dentro da relação.

Em relação às pesquisas futuras, pode-se avançar em questões de assimetria de poder e confiança dentro das governanças entre os agentes dentro de um Sistema Agroindustrial. Pode-se também sugerir o estudo da transação via mercado (spot) utilizada pelos suinocultores independentes e testar o modelo de formas plurais (Silveira, Carrer, Carvalho, Foscaches \& Saes, 2014).

Por fim, este trabalho pode servir de base para estudos sobre estruturas de governança e mecanismo de coordenação em outros Sistemas Agroindustriais. Também pode-se avançar em questões dos efeitos do uso de contratos agrícolas na geração de renda e riqueza para pequenos produtores rurais.

\section{AGRADECIMENTO}

Os autores agradecem os participantes da pesquisa e o Programa de Pós-Graduação em Administração (PPGADM) da Universidade Federal de Goiás (UFG).

\section{CONFLITO DE INTERESSES}

Não houve conflitos de interesse no assunto ou nos materiais discutidos neste manuscrito.

\section{REFERÊNCIAS}

Associação Brasileira dos Criadores de Suínos. (2016). Mapeamento da suinocultura brasileira. Associação Brasileira dos Criadores de Suínos. http://www.abcs.org. br/attachments/-01_mapeamento_completo.pdf

Associação Brasileira de Proteína Animal. (2019). Relatório anual de 2019. Recuperado em 03 de fevereiro de 2020, de http://www.abpa-br.org/mercados/relatorio_ anual_2019.pdf

Alemu, A. E. (2017). Determinants of Smallholders' Preference To Hybrids - Prospect for Upgrading To High-Value Food Chains. Journal of Agribusiness and Rural Development, 10(3). https://doi.org/10.17306/ jard.2016.50

Ambrozini, L. C. S., Martinelli, D. P., Ambrozini, L. C. S., \& Martinelli, D. P. (2017). Formal and relational contracts between organizations: proposal of a model for analysis of the transactional and governance structure characteristics of comparative cases. Revista de Administração, 52(4), 374-391. https://doi.org/10.1016/j. rausp.2017.08.010

Augusto, C. A., Souza, J. P., \& Cario, S. A. F. (2014). Nova Economia Institucional: Vertentes Complementares. Revista Ibero-Americana de Estratégia, 13(01), 93-108. https://doi.org/10.5585/riae.v13i1.2036

Azevedo, P. F. de. (2000). Nova Economia Institucional: referencial geral e aplicações para a agricultura. Agric. São Paulo, 47(1), 33-52.

Bardin, L. (2004). Análise de conteúdo ( $3^{\mathrm{a}}$ ed.). Lisboa: Edições, 70. 
Breitenbach, R., \& Souza, R. S. de. (2015a). Estrutura, conduta e governança na cadeia produtiva do leite: um estudo multicaso no Rio Grande do Sul. REAd. Revista Eletrônica de Administração (Porto Alegre), 21(3), 750781. https://doi.org/10.1590/1413-2311.0372014.53598

Breitenbach, R., \& Souza, R. S. de. (2015b). Estruturas De Mercado, Governança E Poder Na Cadeia Produtiva Do Leite No Rio Grande Do Sul. Organizações Rurais \& Agroindustriais, 17(3), 336-350. https://doi.org/10.22004/ ag.econ.265419

Caleman, S. M. de Q., Zylbersztajn, D., Pereira, M. W. G., \& Oliveira, G. M. de. (2017). Organizational tolerance in agro-industrial systems: an empirical application for the meat sector. Revista de Administração, 52(4), 456-466. https://doi.org/10.1016/j.rausp.2016.11.001

Centro de Estudos Avançados em Economia Aplicada. (2020). PIB do Agronegócio Brasileiro. Recuperado em 08 de fevereiro de 2020, de https://www.cepea.esalq.usp. $\mathrm{br} / \mathrm{br} /$ pib-do-agronegocio-brasileiro.aspx

Coase, R. H. (1937). The Nature of the Firm. Economica, 4(16), 386-405. https://doi.org/10.1111/j.1468-0335.1937. tb00002.x

Dagdeviren, H., \& Robertson, S. A. (2016). A critical assessment of transaction cost theory and governance of public services with special reference to water and sanitation. Cambridge Journal of Economics, 40(6), 1707-1724. https://doi.org/10.1093/cje/bev079

de Almeida, L. F., Zylbersztajn, D., \& Klein, P. G. (2010). Determinants of contractual arrangements in agricultural credit transactions. Revista de Administração, 45(3), 209-220. https://doi.org/10.1016/s0080-2107(16)30476-9

Denzin, N. K., \& Lincoln, Y. S. (Orgs.). (2006). $O$ planejamento da pesquisa qualitativa: teorias $e$ abordagens. Artmed.

de Oliveira, G. M., da Cunha, C. F., Caleman, S. M. D. Q., \& Maia, R. L. G. (2019). Information asymmetry: the case of cattle supply transaction in Brazil. British Food Journal, 121(8), 1825-1837. https://doi.org/10.1108/ BFJ-01-2019-0041

Eisenhardt, K. M. (1989). Building theories from case study research. Academy of management review, 14(4), 532-550.
He, X., Lin, Z., \& Wei, Y. (2016). International market selection and export performance: a transaction cost analysis. European Journal of Marketing, 50(5-6), 916941. https://doi.org/10.1108/EJM-02-2013-0083

Higashi, S. Y., Fagundes, M. B. B., Caleman, S. M. de Q., Sauer, L., \& Saes, M. S. (2017). Plural Forms of Governance at Central Supply Markets. Revista de Administração Contemporânea, 21(6), 743-763. https:// doi.org/10.1590/1982-7849rac2017160166

Kuijpers, R., \& Swinnen, J. (2016). Value chains and technology transfer to agriculture in developing and emerging economies. American Journal of Agricultural Economics, 98(5), 1403-1418. https://doi.org/10.1093/ ajae/aaw069

Lui, S. S., Wong, Y. Y., \& Liu, W. (2009). Asset specificity roles in interfirm cooperation: Reducing opportunistic behavior or increasing cooperative behavior? Journal of Business Research, 62(11), 1214-1219. https://doi. org/10.1016/j.jbusres.2008.08.003

Martins, F. M., Trienekens, J., \& Omta, O. (2017). Governance structures and coordination mechanisms in the Brazilian pork chain - Diversity of arrangements to support the supply of piglets. International Food and Agribusiness Management Review, 20(4), 511-531. https:// doi.org/10.22434/IFAMR2016.0064

Meemken, E. M., \& Bellemare, M. F. (2020). Smallholder farmers and contract farming in developing countries. Proceedings of the National Academy of Sciences of the United States of America, 117(1), 259-264. https://doi. org/10.1073/pnas.1909501116

Ménard, C. (2004). The Economics of Hybrid Organizations. Journal of Institutional and Theoretical Economics, 160(3), 345-376. https://doi.org/10.1628/0932456041960605

Ménard, C. (2018). Research frontiers of new institutional economics. RAUSP Management Journal, 53(1), 3-10. https://doi.org/10.1016/j.rauspm.2017.12.002

Miele, M., \& Waquil, P. D. (2007). Estrutura e dinâmica dos contratos na suinocultura de Santa Catarina: um estudo de casos múltiplos. Estudos Econômicos (São Paulo), 37(4), 817-847. https://doi.org/10.1590/s010141612007000400005 
Miele, M., \& Zylbersztajn, D. (2005). Coordenação e desempenho da transação entre viticultores e vinícolas na Serra Gaúcha. Revista de Administração - RAUSP, 40(4), 330-341.

North, D. C. (1991). Institutions Published by : American Economic Association Institutions. The Journal of Economic Perspectives, 5(1), 97-112.

Oliveira, G. M. de, Zylbersztajn, D., \& Saes, M. S. M. (2019). Can contracts substitute hierarchy? Evidence from high-quality coffee supply in Brazil. British Food Journal, 121(3), 787-802. https://doi.org/10.1108/BFJ01-2019-0048

Passuello, F., Boccaletti, S., \& Soregaroli, C. (2015). Governance implications of non-GM private standards on poultry meat value chains. British Food Journal, 117(10), 2564-2581. https://doi.org/10.1108/BFJ-112014-0380

Paulillo, L. F., \& Neves, M. C. (2015). Análise Das Estruturas De Governança De Compra De Laranja Dos Maiores Packing Houses No Estado De São Paulo: Um Estudo Multicasos Sobre Arranjos Híbridos. Organizações Rurais \& Agroindustriais, 17(4), 461-478.

Poppo, L., \& Zenger, T. (2002). Do formal contracts and relational governance function as substitutes or complements? Strategic Management Journal, 23(8), 707-725. https://doi.org/10.1002/smj.249

Schepker, D. J., Oh, W. Y., Martynov, A., \& Poppo, L. (2014). The Many Futures of Contracts: Moving Beyond Structure and Safeguarding to Coordination and Adaptation. Journal of Management, 40(1), 193-225. https://doi.org/10.1177/0149206313491289

Sexton, R. J. (2013). Market power, misconceptions, and modern agricultural markets. American Journal of Agricultural Economics, 95(2), 209-219. https://doi. org/10.1093/ajae/aas102

Sexton, R. J., \& Xia, T. (2018). Increasing Concentration in the Agricultural Supply Chain: Implications for Market Power and Sector Performance. Annual Review of Resource Economics, 10(1), 229-251. https://doi.org/10.1146/annurevresource-100517-023312
Silva, A. A. da, \& Brito, E. P. Z. (2013). Incerteza, racionalidade limitada e comportamento oportunista: um estudo na indústria brasileira. RAM. Revista de Administração Mackenzie, 14(1), 176-201. https://doi. org/10.1590/S1678-69712013000100008

Silveira, Rodrigo Lanna Franco da, Carrer, Marcelo José, Carvalho, Thiago B., Foscaches, Caroline Acosta Lezcano, \& Saes, Maria Sylvia Macchione. (2014). Formas plurais de governança: uma análise das transações de suprimento entre frigoríficos e pecuaristas. Revista de Economia e Sociologia Rural, 52(4), 761-782. https://dx.doi. org/10.1590/S0103-20032014000400008

Soares, S. de S. S., \& Saes, M. S. M. (2015). Distribuição de combustível no estado de São Paulo: estruturas de governança e mecanismos complementares de coordenação. Revista de Administração, 50(2), 241-253. https://doi.org/10.5700/rausp1197

Verbeke, A., \& Kano, L. (2013). The transaction cost economics (TCE) theory of trading favors. Asia Pacific Journal of Management, 30(2), 409-431. https://doi. org/10.1007/s10490-012-9324-6

Williamson, O. E. (1985). The Economic Institutions of Capitalism. The Free Press.

Williamson, O. E. (1991). Comparative Economic Organization: The Analysis of Discrete Structural Alternatives. Administrative Science Quarterly, 36(2), 269-296.

Williamson, O. E. (1998). Transaction cost economics: how it works; where it is headed. De Economist, 146(1), 23-58.

Williamson, O. E. (2007). Transaction cost economics: An introduction. Economics Discussion Paper, (2007-3).

Williamson, O. E. (2008). Outsourcing: Transaction cost economics and supply chain management. Journal of Supply Chain Management, 44(2), 5-16. https://doi. $\operatorname{org} / 10.1111 / \mathrm{j} .1745-493 X .2008 .00051 . x$

Zhou, L., Zhou, G., Qi, F., \& Li, H. (2019). Research on coordination mechanism for fresh agri-food supply chain with option contracts. Kybernetes, 48(5), 1134-1156. https://doi.org/10.1108/K-08-2017-0291

Organizações Rurais \& Agroindustriais, Lavras, 23:e1655, 2021 
Zylbersztajn, D. (1995). Estruturas de governança e coordenação do agribusiness: uma aplicação da nova economia das instituições. [Tese de Livredocência, Universidade de São Paulo]. https://doi.org/ http://200.144.188.9/

Zylbersztajn, D. (2017). Agribusiness systems analysis: origin, evolution and research perspectives. Revista de
Administração, 52(1), 114-117. https://doi.org/10.1016/j. rausp.2016.10.004

Zylbersztajn, D. (2000). Conceitos Gerais, Evolução e Apresentação do Sistema Agroindustrial. In D. Zylbersztajn \& M. F. Neves (Orgs.). Economia e Gestão dos Negócios Agroalimentares (pp. 1-21). São Paulo: Pioneira. 